Can geriatrics survive?

R G Cooper, MRCP; C J Scott, MRCP; R W Parnell, FRCP; W Fine, FRCP; D R Bodey, BM; S S H Wasty, LAH; F J Fleetwood, FRCGP; G R Burston, MRCPED; A C D

Cayley, MRCP . . . . . . . . . . . . . . . . 1464

Breast-feeding: the immunological argument

J F Soothill, FRCP . . . . . . . . . . . 1467

Establishment of lactation

J M Gurney, мғсм.............. 1467

Encouraging breast-feeding

J G Davies, MrCP.............. 1468

Bottle-feeding

J S Bradshaw, мв. . . . . . . . . . . . . 1468

Alcohol and the brain

C L Brewer, MRCPSYCH. .......... 1468
Drinking drivers and the law

K Norcross, frCs. . . . . . . . . . . . . . . . 1469

Childhood accidents

M J Gilkes, FRCS; J B Tracey, MB . . . . . . 1469

What do community physicians do?

P H M Carson, FRCP. . . . . . . . . . . . . . . . 1469

Intermittent claudication complicating

beta-blockade

A F Lant, FRCP, and D O Gibbons, MRCP . 1469

Older smokers

F E Whitehead, BsC.............. 1469

Vitamin $C$ and the common cold

C W M Wilson, FRCPED............ 1470

Ischaemic heart disease in epileptics

J F Annegers, MD, and D R Labarthe, MD . 1470

Temperature rhythm in

manic-depressive illness

K G Heymann, MRCGP . . . . . . . . . 1470
Fetomaternal haemorrhage and fetofetal transfusion syndrome

Elizabeth $M$ Bryan, MRCP, and Brenda $M$

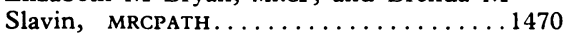

Design of clinical trials

A $P$ Douglas-Jones, MRCs, and J M

Cruickshank, DM..............1471

Power, democracy, and the NHS

C G Eastwood, MD.............1471

Restriction of right to prescribe

B Caplan, MRCGP, and J H Scotson, MRCGP . . 1471

Shortage of British graduates

G W Forrest, MRCGP..............1471

Birmingham meeting on Health

Services Bill

G A Readett, MB . . . . . . . . . 1471
Correspondents are urged to write briefly so that readers may be offered as wide a selection of letters as possible. So many are being received that the omission of some is inevitable. Letters should be signed personally by all their authors.

\section{Can geriatrics survive?}

The letters printed below, some in necessarily abbreviated form, represent only a selection of the many we have received on this subject.

SIR,-Dr J C Leonard's topic for debate (29 May, p 1335) comes at an opportune time, as the British Geriatric Society is at present attempting to define the role of the geriatrician in relation to general medicine. As a member of that society who almost certainly holds a minority view that is broadly in agreement with Dr Leonard's, I consider that many of his suggestions, wer $\epsilon$ they to be adopted, would land us in an even worse plight than that in which we already are. "Why," he asks, "is geriatric medicine necessary as a separate discipline?" Alas, the answer is simple, the same one to the question of why any specialty is necessary. It is that general physicians do not know enough about the elderly ill.

Those of us who practise geriatric medicine have no difficulty in defining what we are about, and to argue that the lack of definition is probably the basic reason why geriatrics has failed to establish itself as an attractive discipline suggests the most superficial knowledge of the subject. True, it has no unique techniques, but good geriatric practice is founded on the same "firm foundation in clinical processes" as good general medicine. Here are some of the basic reasons why geriatrics is not an attractive specialty. The elderly are not attractive because they are a constant reminder of our own fate. We know little about them medically because we have been trained to deal well with acute, short-term problems and to deal even better with them if their solution liolds promise of personal kudos. Such an approach leaves us short of sympathy for the elderly, and short of a philosophy for coping with their chronic illnesses. Working with the elderly is unlikely to gain one entrance to the higher echelons of professional success. Geriatrics is frequently practised in second-class accommodation with second-class equipment and by second-class doctors. Junior staff note all these disadvantages and naturally look elsewhere when planning a successful career.

Staffing of geriatric units is indeed a problem, and integration will go a long way to solve it. General physicians and their junior staff certainly see many elderly patients and they are adequate in coping with emergencies; but they fail when the acute problem is past and they fail because they do not know what to do next. They cannot gauge the possibilities for rehabilitation, they cannot plan a rehabilitation programme, and while they order ancillary help as a routine they seldom discuss the problems with the staff involved. Clinical experience in geriatric units is essential for junior staff. They will be dealing with elderly patients all their working lives, and if they are to practise better medicine than the present generation of physicians specialised experience is necessary, and they will not acquire it in general medical wards.

We are agreed on reintegration, then, but not on the methods. Dr Leonard seems to suggest that all future consultant appointments should be at the subspecialty level so that a specified commitment may be made to the care of the elderly in addition to a recognised interest-for example, in cardiology. If this is his meaning he is ignoring the fact that this is the age of specialisation and it is the general physicians who are in the minority. On the other hand, if he is suggesting that general physicians should all become better geriatricians, leaving the specialists in their chosen fields after persuading them to release the beds previously occupied by patients not requiring their expertise, we are nearer agreement than I appreciate. His ideas of how the care of the elderly might be accomplished, however, perusades me that there is still a wide gulfgeriatricians "might be integrated into the specialty of rheumatology and rehabilitation"; or "physicians might ... divide their geriatric responsibilities on a rotational basis" or "might ... reserve some sessions each week for this work." All this conveys that geriatrics is not only a non-specialty in Dr Leonard's mind but a non-existent specialty. The elderly will get the worst medicine possible from this casual approach. Good geriatric care involves hard, painstaking work based on knowledge and experience which is unlikely to develop in this style of practice.

In this teaching hospital geriatrics is integrated with general medicine to the extent that the geriatricians hold combined appointments, taking their turn on emergency call, and doing ward rounds and clinics, and all junior staff in the department rotate through general medicine. God and the DHSS willing, our new hospital will open next year with three fully integrated medical-geriatric units of 60 beds each and it is expected to provide a better service. Given tha there is no shortage of good applicants for our posts and that this pattern may not be suitable for other regions, any device that gets the geriatrician into the acute ward on day one of the elderly patient's admission is likely to improve the standard of care he gets. The obstacles that must be overcome to achieve this are mainly the attitudes of the people concerned. Geriatricians must enter the medical wards as equals and with the confidence that they have much to offer there. This will remain an insurmountable obstacle for some. Physicians must face the fact that the elderly patient is here for the forseeable future and will not go away if they hide their 
heads in the sand and hope. They have much to learn medically and economically about the care of the elderly and, as Dr Leonard advocates, it is now time for all physicians to share in this work. In general medicine there is no acceptable alternative.

\section{R G COOPER}

Department of Medicine (Geriatrics),

General Hospital,

Newcastle upon Tyne

SIR,-I welcome Dr J C Leonard's challenging paper (29 May, p 1335). It brings into the open for critical examination a dispute between geriatricians and general physicians that quietly smoulders in many districts to the discomfort of both parties. However, I do not accept his solution to the problem of the admitted failure of geriatrics to recruit adequate numbers of staff, nor his reasons for that failure. Should a specialty which is, as he admits, successfully clarifying and making progress towards meeting the needs of a large section of the population, but has recruitment difficulties, really be abolished, while those specialties which have no recruitment problems but whose usefulness to the community do not stand up well to close examination (dare one mention coronary care units?) flourish ? If so, it suggests that Dr Leonard thinks of medicine as a hobby for doctors, where everyone "does his own thing" irrespective of the needs of society.

He suggests that the "lack of definition of the subject is probably the basic reason why geriatrics has failed to establish itself as an attractive discipline." This seems too subtle to be true. Geriatrics, to most medical students and doctors, suggests long-term care in drab, overcrowded, smelly institutions deserted by other specialties and isolated from mainstream medicine, with inadequate nurses and remedial therapists. Such places undoubtedly exist and few would wish to work in them (hence a large number of permanently unfilled consultant posts in geriatric medicine). However, in most areas standards are much better nowadays, but the image remains. Unprecedented progress in medicine over the last 30 years has meant intense competition for teaching time in the undergraduate curriculum. In too many medical schools the geriatrician has been left out in the cold with little chance of improving his image. Indeed, the Todd Report on medical education barely mentions the specialty.

I suspect that Dr Leonard's, and many general physicians', main criticism of geriatrics is that it has failed to clear their "blocked" medical beds. Since the total number of beds available to general physicians and geriatricians is unlikely to increase significantly over the next few years it is unlikely that the number of "blocked" beds will spontaneously diminish. It would seem sensible for the geriatrician to take over the management of these beds. This would cause no hardship to the genera physician, since from his point of view these beds are valueless. It would, however, provide the geriatrician not only with identical facilities but allow him to stand as an equal colleague of the general physician, together providing a comprehensive medical service to all sections of the community. This to me is the real meaning of the word integration, not as $\mathrm{Dr}$ Leonard uses it, to mean the devouring of one specialty by another.

Should an improved teaching programme and equality with general medicine and its other subspecialties fail to improve recruitment I will happily join Dr Leonard's campaign to abolish geriatrics.

C J ScotT

South Lothian District Geriatric Service, Longmore Hospital. Edinburgh

SIR,-Dr J C Leonard (29 May, p 1335) asks whether geriatrics can survive. A more relevant question he might have asked is whether hospital medicine as practised today can survive. For modern medical technology, in its obsessional search for scientific perfection, is extravagant beyond the means available and likely financial support. The attitude of many modern physicians is both negative and narrow.

It is negative in the following sense. At medical school one is taught to make a thorough and systematic search for defects so that those that can be remedied may be treated. Dr Leonard speaks of the multiple pathology "beloved" by geriatricians. Hardly beloved, but it is true that defects accumulate in number with age. $\mathrm{He}$ does not appear to grasp the consequence that so many defects may alter the manner and style of a patient's life and a time comes when, if the patient survives, it is more rewarding to search for the abilities that remain than the defects and the damage that cannot be remedied. The quality of remaining life in a handicapped person depends on positive recognition of personal make-up and spirit. The emphasi should be on what can be done with these qualities to uphold as interesting and satisfying a life as possible in reduced circumstances, and this is what old people so often teach their physicians. Traditional medical teaching leads to the description of a normal person as a mere nobody in whom nothing abnormal has been demonstrated. That is why I say it is negative and requires a more positive approach.

It is also narrow. Let me give two examples. In how many medical notes in teaching hospitals or elsewhere does one find even the simplest summary of a mental examination ? And in the elderly, how many times is the evidence noted for depression, delusional thinking, delirium, or forgetfulness, the central feature of dementia? Yet the first three are specifically treatable and the last needs particular forms of management. Secondly, the narrowness of current attitudes is revealed in the suggestion that geriatrics belongs to medicine. Geriatrics belongs to the NHS; actually to the public who pay for it. The geriatrician serves the old people (and their responsible relatives) who live in the catchment area of a particular district hospital. The promotion of teaching, training and research in specialties such as genera medicine and psychiatry is desirable but secondary; it is not the primary consideration of the NHS. Some specialists, in promoting their specialty, conveniently forget their primary duty. In a unilateral burst of independence they may redefine the limits of what they as specialists are willing to do, irrespective of the needs of the community they have a contract to serve and regardless of the ability or even existence of anyone else to care for the older patients they eschew.

Geriatrics has come to stay because it provides an answer to what the public now needs and, with an aging population, will increasingly demand. Staffing problems, to which
Dr Leonard refers so eloquently, must come second to the main purpose. They could be resolved by more physicians recognising that, for bread and butter reasons if no other, the future lies in following the lead of those who have tackled the problems of old age. This is the way to "unblock" beds, and I may add that there is no such thing as an "acute bed"-only acute need during illness.

The notion of reintegration of geriatrics into a specialty such as "general" medicine is a dying duck-but fortified by much wayward teaching it is certainly taking an unconscionable time to die.

Sutton Coldfield,

R W Parnell W Midlands

SIR,-The weakness of Dr J C Leonard's paper (29 May, p 1335) is that he confuses geriatrics with care of old people in hospital. . . The geriatric syndrome may be defined as a condition occurring in the elderly as a result of disease, which results in an inability to survive within the community.... In my experience the helpless, incontinent, confused elderly patient not only defeats the general physician but is frequently rejected by him as incurable. The number of disease processes which can result in this pattern are enormous. Failure to diagnose them quickly and failure to motivate the nursing team adequately results in the "bed-blocker."

Many of these processes are reversible, and a rapid diagnosis is therefore an essential in this type of case. Making a diagnosis, however, will be ineffective without the back-up of a full rehabilitation organisation. The physician who has not developed a multidisciplinary rehabilitation team of physiotherapists, occupational therapists, and social workers, together with a geriatric day hospital, is as ineffective as a soldier without a gun. The geriatrician not only must have the management technique to develop this complex organisation, he must also develop a district service which can treat many of these patients within the community. This means a domiciliary assessment service co-ordinating with the geriatric day hospital. Can a general physician have the time, or will he have the wish, to develop such a service ? ...

Recruitment problems for geriatric units stem from the law of supply and demand and apply equally to the specialties of ENT, ophthalmology, etc. The first generation of geriatricians were all British-trained, fully experienced general physicians, recruited at a time when ex-majors recently demobilised were jostling for regular consultant posts. At this time the few geriatric units that were being developed had no difficulty in obtaining Britishtrained graduates. Vast expansion of the NHS over the next 10 years resulted in an enormous plethora of posts, both junior and senior, in all the traditional specialties, not only in Britain but parallel with a demand from Australia, America, New Zealand, etc. The supply of graduates from Ireland dried up completely as most of these went to America or Australia.

When, as may well happen, there is a $10 \%$ contraction in junior posts owing to present financial pressures the plethora of posts will disappear and the recruitment picture may well change. The increased intake from medical schools will also have an effect. Up to the present, however, careful selection of overseas graduates has produced many excellent doctors, devoted, humane, and talented, many of them speaking better English than the home product. I count it a privilege to have worked 